\title{
Overexpression of the soybean transcription factor GmDof4 significantly enhances the lipid content of Chlorella ellipsoidea
}

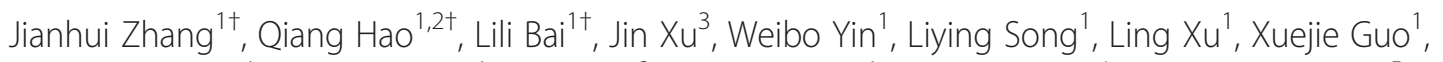
Chengming Fan', Yuhong Chen', Jue Ruan ${ }^{3}$, Shanting Hao', Yuanguang $\mathrm{Li}^{4}$, Richard R-C Wang ${ }^{5}$ and Zanmin $\mathrm{Hu}^{1 *}$

\begin{abstract}
Background: The lipid content of microalgae is regarded as an important indicator for biodiesel. Many attempts have been made to increase the lipid content of microalgae through biochemical and genetic engineering. Significant lipid accumulation in microalgae has been achieved using biochemical engineering, such as nitrogen starvation, but the cell growth was severely limited. However, enrichment of lipid content in microalgae by genetic engineering is anticipated. In this study, GmDof4 from soybean (Glycine max), a transcription factor affecting the lipid content in Arabidopsis, was transferred into Chlorella ellipsoidea. We then investigated the molecular mechanism underlying the enhancement of the lipid content of transformed C. ellipsoidea.

Results: We constructed a plant expression vector, pGmDof4, and transformed GmDof4 into C. ellipsoidea by electroporation. The resulting expression of GmDof4 significantly enhanced the lipid content by 46.4 to $52.9 \%$, but did not affect the growth rate of the host cells under mixotrophic culture conditions. Transcriptome profiles indicated that 1,076 transcripts were differentially regulated: of these, 754 genes were significantly upregulated and 322 genes were significantly downregulated in the transgenic strains under mixotrophic culture conditions. There are 22 significantly regulated genes ( $\log _{2}$ ratio $>1$ ) involved in lipid and fatty acid metabolism. Quantitative real-time PCR and an enzyme activity assay revealed that GmDof4 significantly up-regulated the gene expression and enzyme activity of acetyl-coenzyme A carboxylase, a key enzyme for fatty acid synthesis, in transgenic C. ellipsoidea cells.
\end{abstract}

Conclusions: The hetero-expression of a transcription factor GmDof4 gene from soybean can significantly increase the lipid content but not affect the growth rate of $C$. ellipsoidea under mixotrophic culture conditions. The increase in lipid content could be attributed to the large number of genes with regulated expression. In particular, the acetyl-coenzyme A carboxylase gene expression and enzyme activity were significantly upregulated in the transgenic cells. Our research provides a new way to increase the lipid content of microalgae by introducing a specific transcription factor to microalgae strains that can be used for the biofuel and food industries.

Keywords: Microalgae, Chlorella ellipsoidea, Transcription factor, Lipid accumulation, RNA-seq, Acetyl-coenzyme A carboxylase

\footnotetext{
* Correspondence: zmhu@genetics.ac.cn

${ }^{\dagger}$ Equal contributors

${ }^{1}$ Institute of Genetics and Developmental Biology, Chinese Academy of

Sciences, Datun Road, Chaoyang District, Beijing 100101, China

Full list of author information is available at the end of the article
} 


\section{Background}

Biodiesel is a renewable and environmentally friendly succedaneum for fossil fuels [1]. Many plants have the potential to be used as resources to produce biodiesel; these plants include algae, oilseed rape, soy, and jatropha, of which microalgae have been regarded for decades as the having the highest potential because they can be grown in waste- or seawater [2,3]. Several species of microalgae have higher biomass production rates than those of terrestrial plants [4]. The energy-rich compounds that microalgae produce, such as triacylglycerol (TAG), can be utilized for biodiesel. Some species of microalgae contain a high oil content; these species include Botryococcus braunii with lipid contents of 57 to 64\%, Schizochytrium sp. with lipid contents of 50 to $77 \%$, and Neochloris oleoabundans with lipid contents of 35 to $65 \%$. However, those species grow slowly and have low rates of oil production [5]. In contrast, other species (for instance, Chlamydomonas reinhardtii, Chlorella pyrenoidosa and Navicula pelliculosa) grow rapidly but with low lipid content $(<15 \%)[6,7]$. The desirable algal strains for lipid production should have the best combination of biomass productivity and lipid content, which are often inversely related. Therefore, increasing the lipid content of microalgae with a high growth rate is essential for the production of biodiesel that is synthesized from extracted glycerolipid.

Chlorella ellipsoidea, a unicellular eukaryotic green alga, can be cultured easily under either autotrophic or heterotrophic conditions [8]. In particular, it can be cultivated in industrial wastewater using $\mathrm{CO}_{2}$ that is produced from coal-fired power plants [9]. Compared with other microalgae with a high lipid content, $C$. ellipsoidea has a higher cell growth rate but a slightly lower lipid content $[10,11]$. The average doubling time of C. ellipsoidea on basal medium with glucose is less than 20 hours with a final lipid content of $15 \%[12,13]$. Therefore, increasing the lipid content of C. ellipsoidea while maintaining its cell growth rate could make it a desirable resource for producing biodiesel.

To date, genetic engineering, is more promising for increasing the lipid content of microalgae than controlling the nutritional or culture conditions; the latter has been used to increase the lipid content in several microalgae, but the cell growth was severely limited $[14,15]$. Many encouraging efforts have been reported for the genetic improvement of the lipid content in microalgae. Trentacoste et al. successfully increased microalgal lipid accumulation without compromising the growth in Thalassiosira pseudonana by a knockdown of a multifunctional lipase/phospholipase/ acyltransferase [16]. Niu et al. found that the overexpression of an acyl-Coenzyme A:diacylglycerol acyltransferase gene in Phaeodactylum tricornutum can increase lipid biosynthesis [17]. In addition to genes that are directly related to lipid metabolism, many valuable transcription factors
(TFs) that are involved in the regulation of lipid synthesis in higher plants have been identified in recent years [18]. One excellent example is Dof (DNA binding with one finger) protein, which contains a single $\mathrm{C}_{2} \mathrm{C}_{2}$-type zincfinger-like motif that specifically recognizes an $(\mathrm{A} / \mathrm{T})$ AAAG sequence [19]. Dof plays many crucial roles in regulating many biological processes in plants, including the defense gene expression, seed germination, phytochrome signaling, and photoperiodic control of flowering in Arabidopsis [20], as well as the synthesis of seed storage proteins in Zea mays [21] and the photosynthesis and sucrose transport in Triticum aestivum [22]. In particular, GmDof4, which was found in Glycine max, was involved in lipid synthesis by activating the acetyl-coenzyme A carboxylase (ACCase) gene via direct binding to the cis-DNA elements in its promoter region. The total fatty acid and lipid content in the seeds was significantly increased in GmDof4-transformed Arabidopsis [23].

The aim of this study is to investigate the feasibility and the mechanism for improving the lipid content of C. ellipsoidea by the overexpression of GmDof4. Our results indicated that the lipid content of transgenic C. ellipsoidea cells was increased by 46.4 to $52.9 \%$ under mixotrophic culture conditions, but the contribution of different fatty acids and the growth rate of cells were not significantly affected. Illumina-based RNA-seq results indicated that GmDof4 significantly regulated 1,076 genes of C. ellipsoidea, and 22 of these genes were lipid or fatty acid metabolism genes. Real-time PCR analysis and an enzyme activity assay confirmed that the expression and enzyme activity of ACCase were significantly upregulated in transgenic C. ellipsoidea cells. These findings proved that GmDof4 was able to activate the expression of ACCase genes specifically. Our results also provided a new route for engineering microalgae to increase the lipid content and shed light on the mechanism of lipid accumulation in microalgae regulated by Dof from higher plant.

\section{Results}

\section{Identification of transgenic cells}

In this study, we transformed a plant expression vector, pGmDof4, into C. ellipsoidea by electroporation. pGmDof4 contained GmDof4 under the control of the Ubiquitin promoter and the selection marker gene nptII (Figure 1A). Transformed cells were selected on Selenite Enrichment (SE) agar medium containing $30 \mathrm{mg} / \mathrm{L}$ G418. The selected clones were analyzed by PCR and RT-PCR (Figure 1B) and Southern blot (Figure 1C). The 903 bp GmDof4-specific band from pGmDof4 transgenic strains Dof4-1, Dof4-3, and Dof4-5 was amplified, but not those from control check (CK, the transgenic strain with the pCK that is identical to pGmDof4 but without the GmDof4 expression cassette) and wild type (WT, non-transformed cells) (Figure 1B, top panel). Southern blot results indicated that 
Thus, we concluded that Gmdoft had been integrated into and is normally transcribed in the genome of the C. ellipsoidea.

\section{GmDof4 expression in C. ellipsoidea does not affect the growth}

The growth curves based on the biomass concentration and daily growth rate of the transgenic C. ellipsoidea cells under mixotrophic culture conditions (see Methods) were measured. Under this condition, the transgenic GmDof4 strains, CK, and WT grew in the lag phase for the first two days, in the exponential phase from the third day to the seventh day, and in the stationary phase on the eighth day. The average biomass (dry weight) on the first day was 0.2319 to $0.2348 \mathrm{~g} / \mathrm{L}$, and the maximum biomass was 11.18 to $11.96 \mathrm{~g} / \mathrm{L}$ on the seventh day (Figure 2A). During the exponential stage, the cell-doubling time was approximately 16 hours. The average daily growth rate of the different strains was approximately $0.55 \mu$ /day (Figure 2B). The growth curve and the daily growth rate of the transgenic GmDof4 strains, CK, and WT were similar, suggesting that the pGmDof4 transformation did not have deleterious effects on the growth of C. ellipsoidea cells.

\section{GmDof4 expression in C. ellipsoidea increases the lipid content}

The total soluble protein, carbohydrate, lipid content and composition, and content of fatty acids in the transgenic Gmdof4 strains, CK, and WT were measured under mixotrophic culture conditions. The CK and WT strains had a similar total soluble protein content (average of 15.22\% and $15.50 \%$, respectively), carbohydrate content (average of $35.89 \%$ and $36.15 \%$, respectively), and lipid content (average of $19.02 \%$ and $18.94 \%$, respectively). Compared with CK, all three transgenic GmDof4 strains showed the total soluble protein and carbohydrate content were significantly decreased, while the lipid content was significantly increased. The decrease in the total soluble protein in Dof4-1, Dof4-3, and Dof4-5 was 14.1\%, 9.3\%, and $12.4 \%$, respectively; the decrease in the carbohydrate content was $14.9 \%, 17.1 \%$, and $19.1 \%$, respectively; and, the increase in the lipid content was $49.9 \%, 46.4 \%$, and $52.9 \%$, respectively (Figure $2 \mathrm{C}$ ). The lipid productivity of the transgenic Dof4 strains was 0.45 to $0.47 \mathrm{~g} / \mathrm{L} / \mathrm{d}$, significantly higher than the productivity of WT and CK $(0.31 \mathrm{~g} /$ L/d; Table 1).

The lipid increase in the transgenic GmDof4 strains could also be clearly observed by Nile red staining. More oil droplets accumulated in the transgenic GmDof4 strains than in WT under nutrient-limited conditions (Figure 3A-D). Fluorescence was measured on a Varian 96-well plate spectrofluorometer, and the results showed that the transgenic GmDof4 strains accumulate more TAG when compared to WT cells (Figure 3E). 

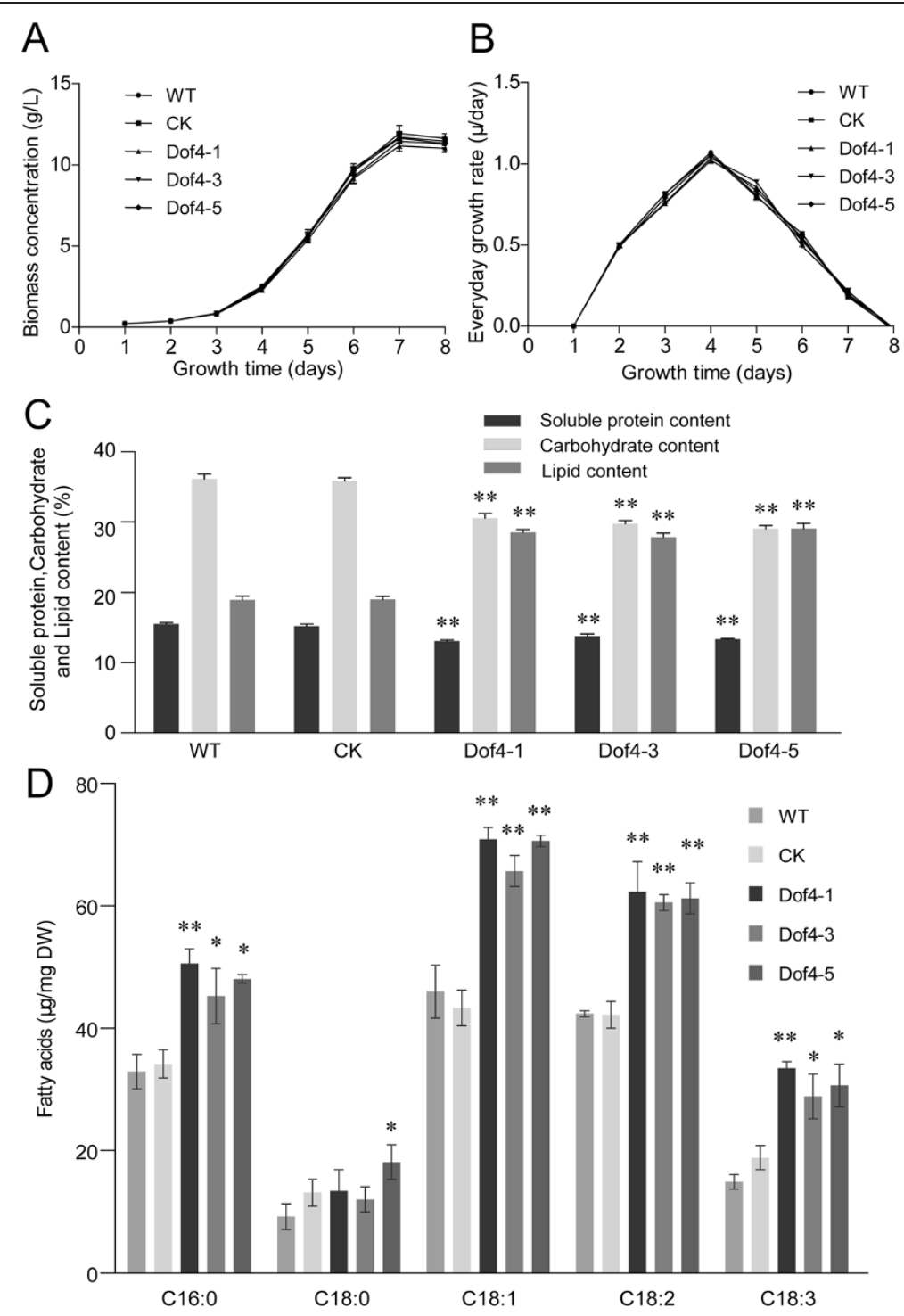

Figure 2 Characterization of transgenic C. ellipsoidea expressing GmDof4 under mixotrophic culture conditions. (A) The growth curves of transgenic GmDof4 Chlorella ellipsoidea under mixotrophic culture conditions for eight days. (B) Growth rate of transgenic GmDof4 strains compared with the control under mixotrophic culture conditions. (C) Total contents of the soluble protein, carbohydrate, and lipid of transgenic GmDof4 Chlorella ellipsoidea under mixotrophic culture conditions. The data represent the means \pm SD of three replicate experiments and were analyzed by Student's t-test $(n=3)$. Asterisks indicate a significant difference from pCK transgenic strains $(* * P<0.01)$. (D) The fatty acid content and composition in transgenic GmDof4 Chlorella ellipsoidea. The data represent the means \pm SD of three replicate experiments and were analyzed by Student's t-test $(n=3) .{ }^{*} P<0.05 ;{ }^{* *} P<0.01$. CK, $\mathrm{pCK}$ transgenic strains; DW, dry weight; WT, wild-type Chlorella ellipsoidea.

Gas chromatograph-mass spectrometry (GC-MS) analysis indicated that the main fatty acid components of the transgenic GmDof4 strains, CK, and WT were similar (Figure 2D); they consisted mainly of palmitic acid (C16:0), stearic acid (C18:0), oleic acid (C18:1), linoleic acid (C18:2), and alpha linolenic acid (C18:3). The abundance of the other fatty acids was too low to mention. With the exception of stearic acid (C18:0), the main fatty acid components of all three transgenic GmDof4 strains showed significant increases. However, the relative compositions of

Table 1 Lipid productivity of Chlorella ellipsoidea under mixotrophic culture conditions

\begin{tabular}{llllll}
\hline & WT & CK & Dof4-1 & Dof4-3 & Dof4-5 \\
\hline Lipid productivity $(\mathrm{g} / \mathrm{L} / \mathrm{d})$ & $0.31 \pm 0.01$ & $0.31 \pm 0.01$ & $0.45 \pm 0.01^{*}$ & $0.45 \pm 0.03^{*}$ & $0.47 \pm 0.03^{*}$
\end{tabular}

The data represent the means \pm SD of three replicate experiments and were analyzed by Student's t-test $(n=3) .{ }^{*} P<0.05$. CK, $p C K$ transgenic strains; WT, wild-type Chlorella ellipsoidea. 

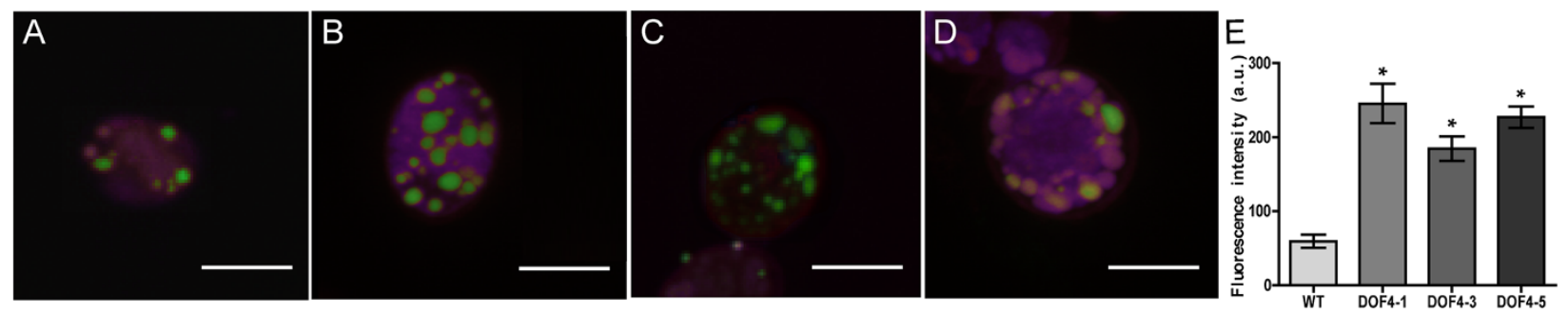

Figure 3 Observation and determination of TAG droplets in Chlorella ellipsoidea under nutrient-limited conditions. (A) WT strain; (B) Dof4-1; (C) Dof4-3; (D) Dof4-5; (E) Fluorescence intensity of Chlorella ellipsoidea. The data represent the means \pm SD of three replicate experiments and were analyzed by Student's t-test $(n=8)$. ${ }^{*} P<0.05$. TAG, triacylglycerol; WT, wild-type Chlorella ellipsoidea.

total fatty acids were not significantly different from that in CK and WT (Table 2).

These results demonstrate that the expression of GmDof4 enhances the lipid synthesis in C. ellipsoidea under mixotrophic culture conditions without any reduced biomass production.

\section{Altered gene expression in transgenic GmDof4 cells under mixotrophic culture conditions}

To understand the cellular mechanisms underlying the transformation of the pGmDof4 construct, transcriptome profiles for the transgenic GmDof4 strain Dof4-1 and the CK samples were performed using the Illumina GAIIx platform. In total, 56,169 contigs with an average length of $441 \mathrm{bp}$ were obtained. The size distribution for these contigs is shown in Additional file 1: Figure S1. The RNA-Seq data can be found in the Gene Expression Omnibus (GEO) library under the accession number [GSE:37473].

Our transcriptome analysis indicated that 1,076 contigs were differentially regulated $\left(\mid \log _{2}\right.$ ratio $\left.\mid>1\right)$, of which 754 contigs, including 421 annotated and 333 unannotated contigs were significantly upregulated, and 322 contigs including 115 annotated and 207 unannotated contigs were significantly downregulated in the transgenic GmDof4 samples. The regulated transcripts were annotated by gene ontology (GO) [24] and classified into hierarchic categories (Figure 4). The most abundant genes were found involved in the membrane and plastids in the cellular components category, protein binding and transferase activity in the molecular function category, and response to stress and transport in the biological process category. Then, we extracted those genes that were associated with fatty acid and lipid metabolism according to the GO annotation in an attempt to understand how GmDof4 regulates the expression of those related genes.

The cumulative distribution of the $\log _{2}$ fold change (Additional file 2: Figure S2) of the transcripts that were associated with fatty acid and lipid metabolism showed a significant right shift, indicating that some transcripts were clearly upregulated. Table 3 lists the significantly regulated transcripts $\left(\mid \log _{2}\right.$ ratio| $\left.>1\right)$ associated with lipid and fatty acid metabolism. Twenty transcripts were significantly upregulated, and two were downregulated significantly. These transcripts included 13 annotated transcripts involved in fatty acid and lipid biosynthesis: seven ACCases, three fatty acid synthases (FASs), one phosphatidylglycerol transferase, and two elongation of very long chain fatty acids proteins. There were three transcripts annotated as fatty acid and lipid transporter: one ATP-binding cassette (ABC) transporter and two Rft-1domain-containing proteins. There were four transcripts involved in fatty acid and lipid catalysis: two phospholipases and two hydrolases. Interestingly, in all 20 upregulated transcripts, the top six (contig IDs: 56171, 80365, 101511, 71421, 67502, and 91597) transcripts and another transcript (contig ID: 59360) were all annotated as ACCases. These results indicated that most of the ACCase transcripts had been significantly upregulated by GmDof4 in C. ellipsoidea.

Table 2 Lipid profile of Chlorella ellipsoidea under mixotrophic culture conditions

\begin{tabular}{llllll}
\hline Fatty acids & Relative percentage & & & \\
\hline & WT & CK & Dof4-1 & Dof4-3 & Dof4-5 \\
C16:0 & $22.64 \pm 2.38$ & $22.52 \pm 2.63$ & $21.91 \pm 1.81$ & $21.31 \pm 2.68$ & $21.01 \pm 0.53$ \\
C18:0 & $6.37 \pm 1.51$ & $8.06 \pm 1.76$ & $5.83 \pm 0.59$ & $5.68 \pm 1.65$ & $7.92 \pm 1.16$ \\
C18:1 & $31.61 \pm 3.15$ & $28.57 \pm 3.32$ & $30.74 \pm 1.43$ & $30.92 \pm 2.07$ & $30.88 \pm 0.70$ \\
C18:2 & $29.14 \pm 0.60$ & $27.82 \pm 2.54$ & $27.01 \pm 3.72$ & $28.49 \pm 1.08$ & $26.77 \pm 1.92$ \\
C18:3 & $10.23 \pm 1.41$ & $12.43 \pm 1.27$ & $14.52 \pm 0.83$ & $13.60 \pm 1.01$ & $13.42 \pm 1.65$ \\
\hline
\end{tabular}

CK, pCK transgenic strains; WT, wild-type Chlorella ellipsoidea. 

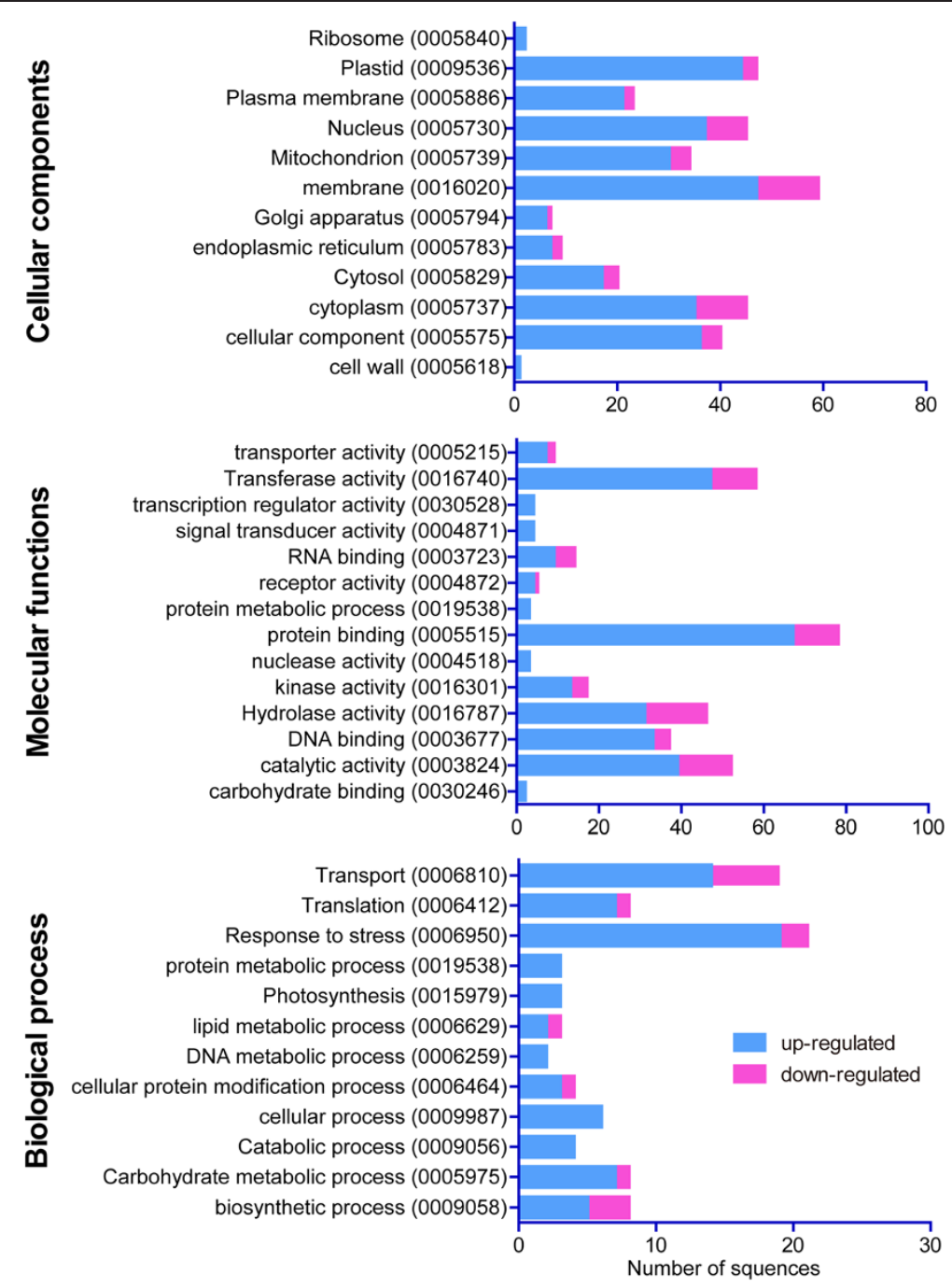

Figure 4 The categories of GmDof4-regulated transcripts in transgenic Chlorella ellipsoidea. The categories of the up- and downregulated transcripts were identified from RNA-seq analysis of the transgenic GmDof4 Chlorella ellipsoidea cells using gene ontology tools.

TFs are able to recognize specific DNA sequences and establish protein-DNA and protein-protein interactions. They affect a large number of genes involved in multiple metabolic pathways, resulting in an integrated, simultaneously up- or downregulation of metabolites in these pathways. In Table 4 , we listed 46 other significantly regulated transcripts $\left(\mid \log _{2}\right.$ ratio $\left.\mid>2\right)$; they were divided according to GO categories into the metabolism (23), transport (6), binding (7), response to stress (4), and unclassified (6) categories. These results indicated that, in addition to the genes involved in lipid and fatty acid metabolism, many other genes with different functions were also strongly regulated by GmDof4 in C. ellipsoidea.

\section{Validation of RNA-seq analysis}

The relative expression levels of 22 significantly regulated transcripts that are associated with lipid and fatty acid metabolism were analyzed by qRT-PCR analysis (Figure 5A). The Chlorella 18S rRNA gene was used as an internal control. Three independent transgenic strains were analyzed. The regulation patterns of 20,10, and 19 transcripts were confirmed by qRT-PCR in Dof4-1, Dof4-3, and Dof4-5, respectively. The results indicated that the expression levels of most of the transcripts detected by qRT-PCR were consistent with those detected by Solexa RNA-seq analysis. However, there were more variations among the different transgenic strains. We also tested the expression of the GmDof4 transcript; there was no expression in CK, and the GmDof4 transcript level in Dof4-1 was higher than that in Dof4-3 and Dof4-5, but similar to that in Dof4-3 and Dof45 (Additional file 3: Figure S3). The variation of the expression levels of the transcripts in different strains may be due to the difference in the integration sites, copy numbers, or other reason caused by nuclear transformation. 
Table 3 Transcripts associated with fatty acid and lipid metabolism that were regulated in transgenic $\mathrm{GmDof4}$ Chlorella ellipsoidea

\begin{tabular}{|c|c|c|c|c|c|}
\hline Contig ID & $\log _{2}$ fold change & Description & NCBI accession & Length & E value \\
\hline 56171 & 8.41 & acetyl-coenzyme a carboxylase & EIE18073.1 & 657 & $1.28 \mathrm{E}-74$ \\
\hline 80365 & 8.38 & acetyl-coenzyme a carboxylase & EIE18073.1 & 600 & 3.76E-61 \\
\hline 101511 & 8.14 & acetyl-coenzyme a carboxylase & EIE18073.1 & 405 & 3.46E-38 \\
\hline 71421 & 7.64 & acetyl-coenzyme a carboxylase & EIE18073.1 & 764 & 4.48E-22 \\
\hline 67502 & 7.19 & acetyl-coenzyme a carboxylase & EIE18073.1 & 570 & 5.75E-74 \\
\hline 91597 & 6.95 & acetyl-coenzyme a carboxylase & EIE18073.1 & 1196 & $9.16 \mathrm{E}-41$ \\
\hline 83574 & 2.93 & elongation of very long chain fatty acids protein 4 & XP_002732296.1 & 1757 & $1.76 \mathrm{E}-36$ \\
\hline 69772 & 1.81 & surface protein Sur1-like protein & EME32697.1 & 317 & $2 \mathrm{E}-25$ \\
\hline 85953 & 1.71 & acetyl xylan esterase & EIE24862.1 & 785 & $5 E-11$ \\
\hline 76019 & 1.58 & phosphatidyl glycerophosphate synthase-like protein & XP_001699073.1 & 592 & $4 \mathrm{E}-15$ \\
\hline 91381 & 1.58 & Rft-1-domain-containing protein & EIE21959.1 & 908 & $4 \mathrm{E}-47$ \\
\hline 85042 & 1.52 & hypothetical protein COCSUDRAFT_48555 & EIE20551.1 & 1569 & $2 \mathrm{E}-69$ \\
\hline 78075 & 1.44 & Rft-1-domain-containing protein & EIE21959.1 & 930 & $9 \mathrm{E}-45$ \\
\hline 88610 & 1.28 & Phospholipase/carboxylesterase & EIE25267.1 & 1196 & $2 \mathrm{E}-68$ \\
\hline 88508 & 1.21 & fatty acid synthase & EIE23140.1 & 658 & $2 \mathrm{E}-83$ \\
\hline 86121 & 1.19 & very-long-chain 3-ketoacyl-CoA synthase & EIE26326.1 & 1535 & $4 \mathrm{E}-129$ \\
\hline 59360 & 1.12 & acetyl co-enzyme A carboxylase BC subunit & EIE26565.1 & 2230 & 0 \\
\hline 83046 & 1.11 & putative phosphatidylglycerol transferase & XP_002947306.1 & 789 & $2 \mathrm{E}-28$ \\
\hline 76421 & 1.07 & fatty acid synthase & EIE23140.1 & 423 & $2 \mathrm{E}-83$ \\
\hline 82144 & 1.02 & SGNH hydrolase & EIE19805.1 & 1721 & $1 \mathrm{E}-31$ \\
\hline 86271 & -1 & PREDICTED: fatty acid synthase isoform X5 & XP_004861076.1 & 617 & 0.00003 \\
\hline 59485 & -1.7 & phospholipase D alpha 2 & NP_175666.1 & 3108 & $3 \mathrm{E}-134$ \\
\hline
\end{tabular}

ACCase activity is enhanced in transgenic C. ellipsoidea cells The ACCase activity was assayed in the transgenic GmDof4 strains and CK (Figure 5B). The ACCase activity of Dof4-1, Dof4-3, and Dof4-5, with average values of $4.25,2.87$, and $3.42 \mathrm{nmol} \mathrm{HCO}_{3} / \mathrm{min} / \mathrm{mg}$ protein, respectively, were significantly higher than that of CK (average value of $1.93 \mathrm{nmol} \mathrm{HCO}_{3} / \mathrm{min} / \mathrm{mg}$ protein). The fact that the ACCase activity was increased was consistent with the additional transcript numbers indicated by the RNA level in transgenic GmDof4 strains.

\section{Discussion}

GmDof4 expression in C. ellipsoidea increases the lipid content but does not affect the growth

Microalgae are an attractive renewable biodiesel feedstock because their productivity is 20 to 40 times higher than that of oil crops [25]. Rapidly growing algal cells, which are suited for large-scale production in highly variable outdoor conditions, contain lower amounts of lipid ( $\leq 20 \%$ of dry weight), whereas algal cells with high lipid contents (40 to $50 \%$ of dry weight) grow very slowly [26]. Increasing the lipid content of rapidly growing microalgae is a desirable approach to producing biodiesel by cell culture. To date, significant advances in microalgal genomics have been achieved [6,27], and two reports of enhanced lipid content of diatoms due to genetic engineering have been published [16,17].

In this research, we transferred GmDof4 into the unicellular eukaryotic organism C. ellipsoidea, and we found that the total lipid content of GmDof4 transgenic C. ellipsoidea was increased by 46.4 to $52.9 \%$ relative to that of CK under mixotrophic culture conditions. In contrast, the overexpression of GmDof4 in Arabidopsis resulted in an increase in the seed lipid content by $22 \%$ over that of wildtype plants [23]. To our knowledge, this is the first report of significantly increasing the lipid content of Chlorella by genetic engineering. Along with the clearly increased total lipid content, the total soluble protein and carbohydrate content were significantly decreased in GmDof4 transgenic C. ellipsoidea expressing GmDof4. These results indicated that there is a balancing system that regulates metabolism and energy exchange in transgenic C. ellipsoidea cells.

However, we found that the growth curve and the growth rate of transgenic GmDof4 C. ellipsoidea were not different from those of $\mathrm{CK}$ and WT under mixotrophic culture conditions in the Endo medium (Figure 2A,B). This result suggested that the GmDof4 expression in C. ellipsoidea did not have a deleterious effect on the 
Table 4 Transcripts regulated in transgenic GmDof4 Chlorella ellipsoidea

\begin{tabular}{|c|c|c|c|c|c|c|}
\hline Function classification & Contig ID & $\log _{2}$ fold change & Description & NCBI accession & Length & E value \\
\hline \multirow[t]{23}{*}{ Metabolism } & 88349 & 5.10 & flavodoxin & EIE22982.1 & 943 & $1.01 \mathrm{E}-46$ \\
\hline & 80694 & 3.09 & flavin-containing monooxygenase & XP_001690742.1 & 318 & $1.43 \mathrm{E}-07$ \\
\hline & 81782 & 3.00 & serine/threonine-protein kinase TOUSLED-like & XP_003545185.1 & 428 & $6.59 \mathrm{E}-13$ \\
\hline & 86913 & 2.93 & tousled-like kinase 1 & XP_002957155.1 & 656 & 1.09E-09 \\
\hline & 83574 & 2.93 & elongation of very long chain fatty acids protein 4 & XP_002732296.1 & 1757 & $1.76 \mathrm{E}-36$ \\
\hline & 67904 & 2.92 & sodium sulfate co-transporter & XP_001690490.1 & 1201 & 4.7E-101 \\
\hline & 65347 & 2.84 & sodium sulfate co-transporter & XP_001690491.1 & 1927 & 3.7E-136 \\
\hline & 91555 & 2.76 & serine threonine-protein kinase tousled-like 2 & XP_002127920.1 & 360 & $3.24 \mathrm{E}-12$ \\
\hline & 81781 & 2.67 & serine/threonine-protein kinase tousled-like & XP_003082583.1 & 848 & 1.1E-18 \\
\hline & 82347 & 2.64 & ATP-dependent RNA helicase & EIE18729.1 & 1571 & $1.27 \mathrm{E}-13$ \\
\hline & 85841 & 2.59 & ferric-chelate reductase & EIE26078.1 & 1533 & $4 \mathrm{E}-50$ \\
\hline & 62217 & 2.47 & hexokinase 2 & EIE26809.1 & 3014 & $1.3 \mathrm{E}-80$ \\
\hline & 73871 & 2.37 & cinnamyl alcohol dehydrogenase & EIE22193.1 & 1012 & 4.3E-54 \\
\hline & 79933 & 2.36 & cytosine-5 DNA methyltransferase & XP_003561341.1 & 340 & 8.97E-39 \\
\hline & 81062 & 2.18 & ubiquitin thioesterase & EIE18214.1 & 1460 & $6.56 \mathrm{E}-79$ \\
\hline & 89786 & 2.05 & transcription initiation factor TFIID subunit 6-like & XP_003577929.1 & 345 & $6.85 \mathrm{E}-26$ \\
\hline & 93291 & -5.51 & cytochrome P450 & EIE19060.1 & 527 & 0.000213 \\
\hline & 83571 & -2.59 & alpha/beta-hydrolase & EJD50872.1 & 940 & $1.91 \mathrm{E}-29$ \\
\hline & 72299 & -2.53 & endoribonuclease I-psp & YP_002251050.1 & 855 & $1.99 \mathrm{E}-11$ \\
\hline & 68852 & -2.43 & fad linked oxidase domain protein & YP_001699676.1 & 1274 & $1.11 \mathrm{E}-15$ \\
\hline & 68856 & -2.26 & FAD-dependent oxidoreductase & YP_001252809.1 & 776 & $6.45 \mathrm{E}-32$ \\
\hline & 76145 & -2.23 & serine threonine protein kinase 9 & EIE18318.1 & 893 & $1.68 \mathrm{E}-32$ \\
\hline & 59899 & -2.12 & hydroxydechloroatrazine ethylaminohydrolase & EIE19019.1 & 1628 & $1.6 \mathrm{E}-124$ \\
\hline \multirow[t]{6}{*}{ Transport } & 58206 & 3.41 & Snf7-domain-containing protein & EIE26516.1 & 765 & $7.21 \mathrm{E}-20$ \\
\hline & 56450 & 2.54 & sugar transport protein & EIE22371.1 & 2478 & $3.4 \mathrm{E}-116$ \\
\hline & 62118 & 2.19 & sugar transport protein & EIE26164.1 & 2507 & $1.23 \mathrm{E}-97$ \\
\hline & 70774 & -4.03 & hypothetical protein CHLNCDRAFT_145405 & EFN56009.1 & 1016 & 0.000108 \\
\hline & 62487 & -3.06 & uric acid-xanthine permease & XP_001690343.1 & 959 & 4.3E-69 \\
\hline & 80480 & -2.1 & purine permease & XP_002152129.1 & 542 & $2.09 \mathrm{E}-24$ \\
\hline \multirow[t]{7}{*}{ Binding } & 76355 & 3.59 & zinc finger protein zf1 & XP_003081226.1 & 1037 & $3.55 \mathrm{E}-11$ \\
\hline & 59250 & 3.58 & f-box protein & YP_007198.1 & 975 & $1.96 \mathrm{E}-16$ \\
\hline & 79167 & 3.09 & p115-like protein & NP_566820.1 & 1230 & $1.48 \mathrm{E}-49$ \\
\hline & 92615 & 3.08 & argonaute protein group & EIW84641.1 & 417 & $2.61 \mathrm{E}-25$ \\
\hline & 77846 & 2.72 & f-box protein/LRR-repeat protein & EIE24729.1 & 1000 & $2.73 \mathrm{E}-11$ \\
\hline & 84262 & 2.62 & hsp100 family & EIE26713.1 & 2508 & 0 \\
\hline & 99456 & 2.08 & Zinc-finger protein & XP_002007677.1 & 327 & 0.000952 \\
\hline \multirow[t]{4}{*}{ Response to stress } & 86306 & 3.58 & heat shock protein hsp20 & EFN56197.1 & 939 & $3.27 \mathrm{E}-13$ \\
\hline & 86715 & 3.03 & kda class i heat shock protein 1 & EFN56197.1 & 1089 & $9.83 \mathrm{E}-15$ \\
\hline & 72405 & 2.36 & heat shock transcription factor 1 & XP_001694420.1 & 1239 & 4.37E-25 \\
\hline & 86717 & 2.28 & heat shock protein 17 & EFN56197.1 & 746 & $9.6 \mathrm{E}-22$ \\
\hline \multirow[t]{3}{*}{ Unclassified } & 58160 & 2.79 & vesicle docking protein & XP_003079367.1 & 1828 & $2.61 \mathrm{E}-14$ \\
\hline & 87605 & 2.25 & hypothetical protein CHLNCDRAFT_32684 & EFN52166.1 & 506 & $3.29 \mathrm{E}-20$ \\
\hline & 89602 & 2.06 & predicted protein & XP_001689881.1 & 312 & $6.48 \mathrm{E}-05$ \\
\hline
\end{tabular}


Table 4 Transcripts regulated in transgenic GmDof4 Chlorella ellipsoidea (Continued)

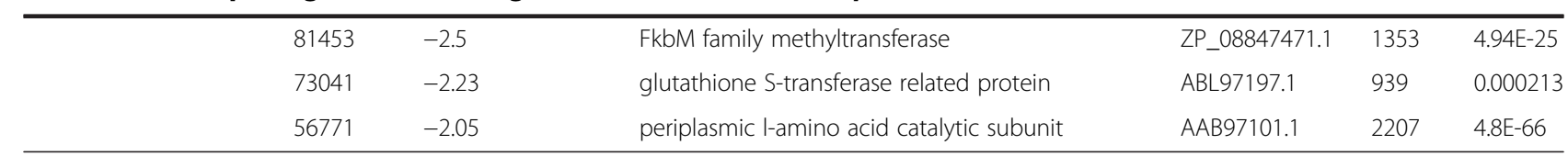

The transcripts associated with fatty acid and lipid metabolism were excluded.

growth of host cells although the GmDof4 originated from a higher plant. Using TFs to engineer microalgae for increased the lipid content without decreasing the growth rate of host cells is a significant advance. Certainly, scaledup culture must still to be tested for biodiesel production.

To determine whether more carbon was entering the cell via mixotrophic growth, we measured the growth rate and lipid content of the transgenic C. ellipsoidea expressing GmDof4 under an autotrophic culture condition. This condition did not significantly change the growth, but the lipid productivity was still increased in transgenic GmDof4 strains (Additional file 4: Figure S4; Additional file 5: Table S1). These results indicated that the increased lipid content might result from the conversion of internal source of carbon rather than an exogenous carbon input.

We also found that all three transgenic GmDof4 strains showed significant increases in the absolute content of C18:1, C18:2, C18:3, and C16:0 fatty acids compared with those in CK, but there was no significant difference in the relative content of these main fatty acids under mixotrophic culture conditions (Table 2). In contrast, the relative level of C18:2 was significantly decreased in GmDof4 transgenic Arabidopsis plants [23]. This result suggested that the expression of GmDof4 in different organisms may result in a shift of certain fatty acid component.

\section{GmDof4 significantly regulated the gene expression of C. ellipsoidea}

GmDof4 is a flower/pod-specific gene and can increase the lipid content and weight of Arabidopsis seeds by regulating the gene expression network involved in lipid biosynthesis. In Arabidopsis, the expression of 104 genes was upregulated and that of 64 genes was downregulated by GmDof 4 [23]. Our results indicated that the expression of 754 genes was significantly upregulated and that of 322 genes was significantly downregulated in transgenic GmDof4 C. ellipsoidea. In this regulatory network, the transcripts of ACCase became the center of attention.

ACCase catalyzes the first key step of fatty acid biosynthesis in a two-step reaction that results in the conversion of acetyl-CoA to malonyl-CoA. Most plants have two forms of ACCase: a homomeric form in the cytosol that is composed of a single large polypeptide catalyzing the individual carboxylation reactions, and a heteromeric form in plastids that is composed of four subunits [biotin carboxylase $(\mathrm{BC})$, biotin carboxyl carrier protein
(BCCP), $\alpha$-carboxyl transferase $(\alpha-\mathrm{CT})$, and $\beta$-carboxyl transferase $(\beta-C T)][28,29]$. Guarnieri et al. [30] reported that the ACCase abundance was upregulated approximately two-fold in Chlorella vulgaris strain UTEX 395 under nitrogen-depleted conditions. Using microarray and DNA-binding analysis, the GmDof4 protein was previously shown to activate $a c c D$ expression by directly binding the promoter of $a c c D$ at position -287 to -274 in transgenic Arabidopsis [23]. Using RNA-seq and qRTPCR, we found that seven transcripts encoding ACCase were significantly upregulated. In particular, the top six up-regulated transcripts (contig IDs: 56171, 80365, 101511, 71421, 67502, and 91597) were all annotated as ACCase. Transcriptome analysis and conservative binding region comparisons [31] revealed that the genes that encode both forms of ACCase in transgenic GmDof4 C. ellipsoidea. Contig ID 59360 is a part of heteromeric form of ACCase biotin carboxylase (BC) subunit gene that was significantly upregulated in transgenic GmDof4 C. ellipsoidea (Table 3), whereas contig ID 56174 is a part of a homomeric form of the ACCase BC subunit gene that was not significantly regulated in transgenic GmDof4 C. ellipsoidea. However, we could not identify the form of the other six upregulated ACCase genes because the sequence information was incomplete. Nevertheless, it is certain that GmDof4 protein strongly upregulates ACCase in transgenic C. ellipsoidea cells. Using an enzyme activity assay analysis, we confirmed that the ACCase activity was significantly increased in transgenic C. ellipsoidea cells in the exponential phase. However, the detailed mechanism of the regulation of ACCase enzyme activity by the GmDof4 protein in C. ellipsoidea must still be investigated. Future studies will aim at obtaining the GmDof4-binding regions of ACCase genes, which are usually the promoter regions of these genes.

In addition to ACCase genes, FAS gene, and phospholipase $\mathrm{D}$ gene were significantly regulated in transgenic GmDof4 C. ellipsoidea in the exponential phase. FAS is a multi-enzyme system that catalyzes fatty acid synthesis. Its main function is to catalyze the synthesis of palmitate from acetyl-CoA and malonyl-CoA, in the presence of reduced nicotinamide adenine dinucleotide phosphate (NADPH), into long chain saturated fatty acids. Phospholipase D is an enzyme that catalyzes the hydrolysis of phosphatidylcholine to form the phosphatidic acid (PA) that is involved in lipid degradation [32]. These results demonstrated the pivotal role of the GmDof4 protein in lipid and fatty acid metabolism. 


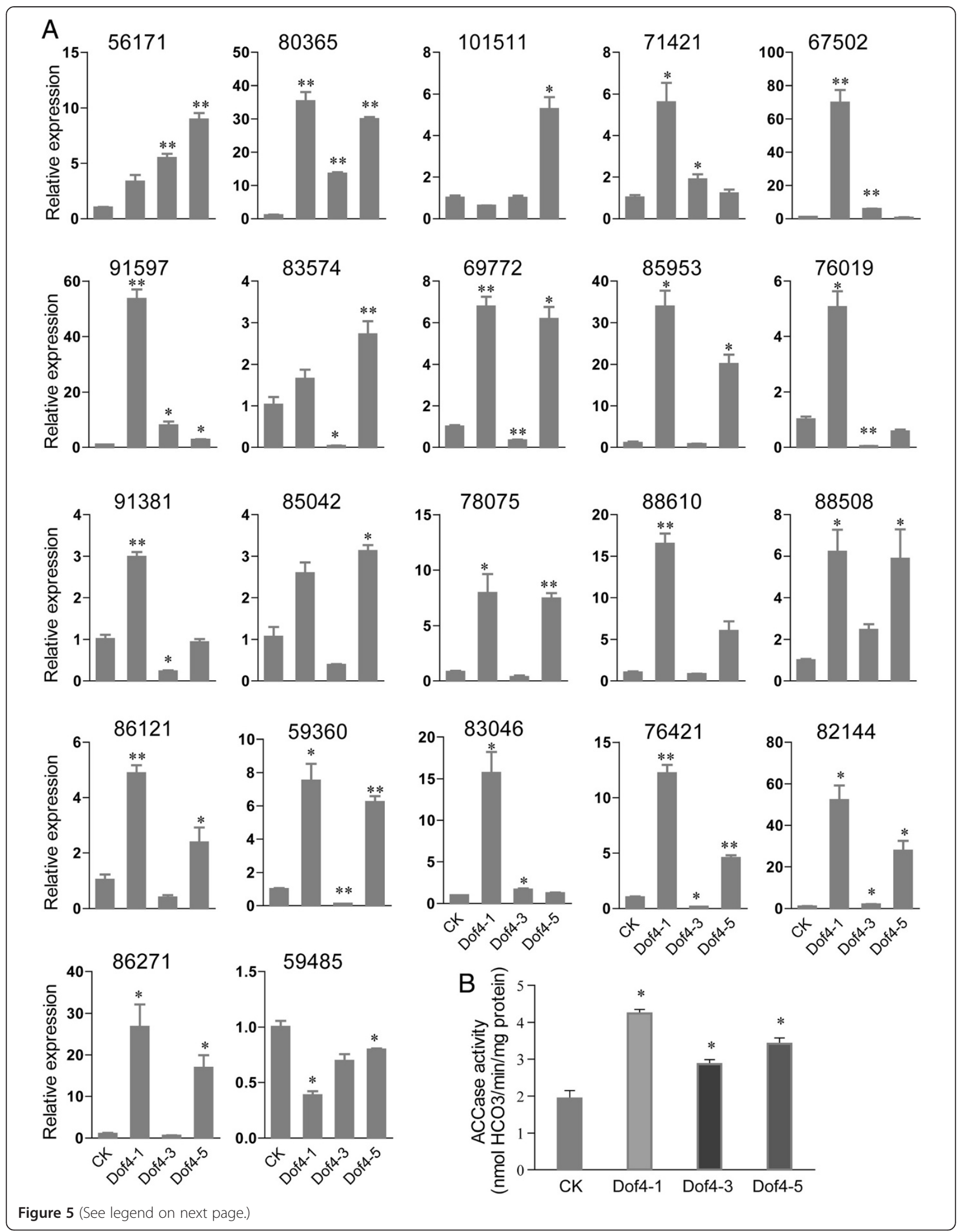


(See figure on previous page.)

Figure 5 Validation of RNA-seq by qRT-PCR and an enzyme activity assay. (A) Gene expression detected by qRT-PCR in Chlorella ellipsoidea. The relative expression of 20 upregulated and two downregulated genes related to lipid and fatty acid metabolism was determined by qRT-PCR. The data represent the means \pm SD of three replicate experiments and were analyzed by Student's t-test $(n=3)$. ${ }^{*} P<0.05$; ${ }^{* *} P<0.01$. (B) ACCase activity in crude cell extracts of CK and transgenic GmDof4 strains. The data represent the means \pm SD of three replicate experiments and were analyzed by Student's t-test $(n=3) .{ }^{*} P<0.05$. ACCase, acetyl-coenzyme A carboxylase; CK, pCK transgenic strains.

The Dof proteins are thought to regulate the expression of particular genes via binding to the promoter or via specific protein-protein interactions. In our study, we classified the significantly regulated genes from transcriptome analysis into binding (seven upregulated genes), metabolism (22 upregulated genes, and seven downregulated genes), response to stress (four upregulated genes), and transport (three upregulated genes and three downregulated genes) categories using GO tools. Some of the genes regulated by the GmDof4 protein in transgenic Arabidopsis and C. ellipsoidea are the same, such as ACCase beta subunit, glutathione S-transferase, and cytochrome P450, but there are still many different genes that are regulated in different species, such as $12 \mathrm{~S}$ seed storage protein (CRA1) and male sterility MS5 family protein. These differences could be caused by the great genomic diversity between higher plant and unicellular green alga. In short, GmDof4 may play a comprehensive role in the increase total lipid content and may regulate genes related to lipid, fatty acid, protein, and carbohydrate metabolism in transgenic C. ellipsoidea cells. Certainly, the network of target genes regulated by GmDof4 in C. ellipsoidea needs to be characterized further in detail.

Although complete genome sequences from the unicellular green algae Chlorella variabilis NC64A have been obtained [33], little is known about the transcription factors involved in lipid metabolism. Recent advances in systems biology analyses of unsequenced microalgae could provide new tools to accelerate the production of next-generation biodiesel [34]. Moreover, using transcriptomics and proteomics to examine the triacylglycerol biosynthetic pathway in C. vulgaris will greatly accelerate the commercialization of microalgae-derived biodiesel $[30,35]$. These efforts establish a foundation for elucidating the key components of microalgal lipid productivity enhancement. Our results suggested that a TF from higher plants could be used to improve the lipid content of C. ellipsoidea and, most likely, other species.

\section{Conclusions}

The hetero-expression of a gene for a transcription factor, GmDof4, from soybean (G. max) can significantly increase the lipid content while not affecting the growth rate of $C$. ellipsoidea under mixotrophic culture conditions. The increase of lipid content could be attributed by GmDof4 gene regulatory network that enhances ACCase gene expression and enzyme activity in the transgenic cells. Our research provides a new way to increase the lipid content of microalgae by introducing a specific transcription factor to microalgae strains that can be used by the biofuel industry.

\section{Methods}

\section{Strains and culture conditions}

The C. ellipsoidea cells used in this study were grown in Endo medium [36] for the mixotrophic culture and in KNOP medium [37] for the autotrophic culture in a rotary shaker (DZ-900, Zhongkepusen Co., Ltd., Beijing, China), $200 \mathrm{rpm}$ at $25^{\circ} \mathrm{C}$ under illumination $(100 \mu \mathrm{mol}$ photons $/ \mathrm{m}^{2} / \mathrm{s}$ ).

\section{Cloning of GmDof4 cDNA}

The cDNA of GmDof4 was amplified from leaves of soybean cultivar Kefeng 1 using primers P1 and P2 (Additional file 6: Table S2), which were designed according to the published GmDof4 cDNA sequence (accession number: [GenBank: DQ857254.1]). The GmDof4 cDNA was cloned into a T-vector (pEASY-Blunt Cloning Vector, TransGen Biotech. Ltd., Beijing, China) resulting in pEB-GmDof4.

\section{Construction of the Gmdof4 plant expression vector}

The Nopaline synthase (nos) terminator was amplified by PCR with primers P3 and P4 (Additional file 6: Table S2) from plasmid vector pGreen0029 (Biotechnology and Biological Sciences Research Council, BBSRC, Wiltshire, United Kingdom) and was cloned into the site between Not I and Sac I in pGreen0029, resulting in an intermediate vector pGreen0029-Tnos. The ubi promoter region from maize [38] was amplified by PCR from plasmid vector pBI221 (Clontech Laboratories Inc., Mountain View, United States) with primers P5 and P6 (Additional file 6: Table S2) and cloned into the site between Hind III and BamH I in pGreen0029-Tnos, resulting in a vector pGreen0029-Pubi-Tnos (pCK) that confers resistance to the aminoglycoside antibiotics, such as G418. The DNA fragments encoding GmDof4 were obtained by digesting the pEB-GmDof4 with Spe I and Not I, and the fragments were then inserted into the site between Spe I and Not I in the plastid PCK at the downstream of the ubi promoter, resulting in vector pGreen0029-UbiGmDof4-Nos (pGmDof4). 


\section{Transformation of C. ellipsoidea}

C. ellipsoidea was transformed according to a previously published method [39]. Briefly, cells were cultured to the logarithmic phase in Endo medium $(10 \mathrm{~mL}$, containing approximately $10^{7}$ cells $/ \mathrm{mL}$ ), collected by centrifugation and resuspended in $10 \mathrm{~mL}$ of a solution of $0.2 \mathrm{M}$ mannitol and 0.2 M sorbitol (Sigma Aldrich, St. Louis, United States). The resuspended cells were kept on ice for 1 hour, centrifuged and resuspended in electroporation buffer (0.08 M KCl, 0.005 M CaCl2, 0.01 M HEPES, 0.2 M mannitol, and $0.2 \mathrm{M}$ sorbitol) at a concentration of approximately $10^{8}$ cells $/ \mathrm{mL}$ and then immediately mixed with a final concentration of $20 \mu \mathrm{g} / \mathrm{mL}$ pGmDof4 plasmid, a final concentration of $10 \mu \mathrm{g} / \mathrm{mL}$ plasmid pSoup, and $25 \mu \mathrm{g} / \mathrm{mL}$ salmon sperm DNA (Invitrogen, Carlsbad, CA, United States). In total, $0.4 \mathrm{~mL}$ of the cell suspension was removed, kept on ice for 5 to 10 minutes, and subsequently used for transformation. The cells were transformed with a Baekon 2000 (Baekon Co., California, United States) electroporation device using $6 \mathrm{kV}$ of between 0.001 and 0.02 second pulse duration, $2^{10}$ pulse frequency and $2 \mathrm{~mm}$ pulse distance for 100 cycles. After electroporation, the cells were screened using SE agar [40] selection medium containing $30 \mathrm{mg} / \mathrm{L} \mathrm{G418}$. The individual clones on the selection medium could be obtained after 25 to 30 days and they were continuously selected once per month for at least eight times. The selected individual strains were subcultured in SE liquid medium containing $15 \mathrm{mg} / \mathrm{L}$ G418.

\section{Transgenic cells identification by PCR and RT-PCR}

The individual clones grown on the selection medium were subcultured in SE liquid medium with $15 \mathrm{mg} / \mathrm{L}$ G418. The cells at a cell density of approximately $1 \times 10^{8}$ cells $/ \mathrm{mL}$ were collected by centrifugation at $12,000 \mathrm{~g}$ for 10 minutes. The DNA was extracted using the hexadecyl trimethyl ammonium bromide (CTAB) method. GmDof4 was detected by PCR using primers 1 and 2 (Additional file 6: Table S2). The PCR products were analyzed by electrophoresis on a 1\% agarose gel (Gene Company Ltd., Hong Kong, China) and sequenced by SinoGenoMax Co., Ltd., (Beijing, China). For RT-PCR detection, the RNA was isolated from the cells using the guanidinium thiocyanate-phenol-chloroform extraction procedure [41]. The expression of GmDof4 and $n p t$ II was detected by RT-PCR using primers 9 and 10 and primers 11 and 12 (Additional file 6: Table S2), respectively, which were designed on the basis of coding region of the GmDof4 and npt II genes. RT-PCR products were analyzed by electrophoresis on a $1 \%$ agarose gel and by sequencing.

\section{Southern blot analysis}

Approximately $20 \mu \mathrm{g}$ of genomic DNA of PCR identified transgenic clones was separately digested with different restriction endonucleases, separated on a $0.8 \%$ agarose gel, blotted onto a nitrocellulose membrane (Amersham Bioscience, Little Chalfont, United Kingdom) and hybridized with the probe that was amplified from the vector pGmDof4 by the primers P7 and P8 (Additional file 6: Table S2), which were designed on the basis of part of the coding region of the GmDof4 gene. The probe was labeled with dCTP $\alpha-{ }^{32} \mathrm{P}$ using a random primer labeling kit (Takara Biotechnology Co., Ltd., Dalian, China). The hybridization was performed according to the description by Sambrook and Russell [42].

\section{Biomass analyses}

All the biomass analyses were performed using transgenic and wild-type $C$. ellipsoidea strains grown in $100 \mathrm{~mL}$ of Endo medium and grown in KNOP medium for autotrophic culture in a rotary shaker at $25^{\circ} \mathrm{C}$ under illumination $\left(100 \mu \mathrm{mol}\right.$ photons $\left./ \mathrm{m}^{2} / \mathrm{s}\right)$.

The C. ellipsoidea biomass concentration $(\mathrm{w} / \mathrm{v})$ is equivalent to a specific value of the cell dry weight (DW) that was determined by $\mathrm{OD}_{540}$ according to the following empirical formula:

$$
D W(g / L)=\left(O D_{540}+0.0097\right) / 0.4165
$$

The specific growth rate of $C$. ellipsoidea was calculated according to the equation [43]:

$$
\operatorname{SGR}(\mu / \text { day })=\ln \left(X_{2}-X_{1}\right) /\left(t_{2}-t_{1}\right)
$$

where $X_{1}$ is initial biomass concentration, $X_{2}$ is ending biomass concentration, and $\left(t_{2}-t_{1}\right)$ is elapsed time.

Measurement of the soluble proteins, carbohydrate, lipid content, and the fatty acid composition

Transgenic and wild-type C. ellipsoidea strains were cultured in Endo medium in a rotary shaker at $25^{\circ} \mathrm{C}$ under illumination $\left(100 \mu \mathrm{mol}\right.$ photons $\left./ \mathrm{m}^{2} / \mathrm{s}\right)$ for seven days. The biomass was collected to measure the soluble proteins, carbohydrate, lipid content, and the fatty acid composition.

\section{Detection of proteins and carbohydrate}

Calibration curves were generated for each of the cellular constituents using D-glucose for carbohydrate (Beijing Chemical Works, Beijing, China). The carbohydrate content was analyzed based on the procedure published by Miao and $\mathrm{Wu}$ [44]. In short, $0.1 \mathrm{~g}$ of dried algal pellet was acidified by adding $20 \mathrm{~mL}$ of $2.5 \mathrm{M} \mathrm{HCl}$ (Beijing Chemical Works, Beijing, China). The acidified solution was then hydrolyzed at $100^{\circ} \mathrm{C}$ for 30 minutes and neutralized to $\mathrm{pH}$ 7. The volume was adjusted to $100 \mathrm{~mL}$. The filtered sample was subjected to a 3,5-dinitrosalicylic acid (DNS) assay. Proteins were extracted following the procedure of Rausch [45] and were quantified using the Bradford method [46]. 


\section{Lipid content measurement}

Lipid extraction was performed by the Soxhlet method that was similar to the procedures reported by Folch et al. [47]. Briefly, the total biomass was harvested by low-temperature centrifugation, washed with distilled water, frozen at $-20^{\circ} \mathrm{C}$, freeze-dried for 24 hours, and then gravimetrically determined. The cell paste was dried at $40^{\circ}$ $\mathrm{C}$ for 12 hours and then the dry biomass was ground into powder. Accurately weighed $0.5 \mathrm{~g}$ of the powder was mixed with $125 \mathrm{~mL}$ trichloromethane:methanol (2:1, v/v) solvent (Beijing Chemical Works, Beijing, China). The extraction was performed at $100^{\circ} \mathrm{C}$ for 4 hours to ensure maximum recovery. The lipid was recovered using a rotating vacuum evaporator.

\section{Lipid productivity calculation}

Daily lipid productivity was calculated using the equation:

$$
\begin{aligned}
& \text { Daily lipid production }(\mathrm{g} \text { lipid/ } \mathrm{L} / \text { day) } \\
& =\mathrm{DW} \times \text { lipid content } / \text { day }
\end{aligned}
$$

where DW is algal dry weight ( $\mathrm{g} / \mathrm{L})$, lipid content is \% $\mathrm{DW}$, and day is growth period.

\section{Fatty acid composition detection}

The fatty acid composition was qualitatively and quantitatively determined using a TurboMass gas chromatography mass spectrometer (PerkinElmer, Massachusetts, United States) with a capillary column (BPX-70, $30 \mathrm{~m} \times$ $0.25 \mathrm{~mm} \times 0.25 \mu \mathrm{m})$ using the method described by Kattner and Fricke [48] and Song et al. [49]. Briefly, cellular fatty acid was extracted from $50 \mathrm{mg}$ of C. ellipsoidea powder in $3 \mathrm{~mL}$ of $7.5 \%(\mathrm{w} / \mathrm{v})$ potassium hydroxide in methanol for saponification at $70^{\circ} \mathrm{C}$ for 3 hours. After the $\mathrm{pH}$ was adjusted to 2.0 with hydrochloric acid, the fatty acids were subjected to methyl esterification with $2 \mathrm{~mL}$ of $14 \%(\mathrm{w} / \mathrm{v})$ boron trifluoride in methanol (Beijing Chemical Works, Beijing, China) at $70^{\circ} \mathrm{C}$ for 1.5 hours. Then $1 \mathrm{~mL}$ of $0.9 \%(\mathrm{w} / \mathrm{v})$ sodium chloride was added and was mixed well. Subsequently, fatty acid methyl esters (FAMEs) were extracted with $4 \mathrm{~mL}$ of hexane (Beijing Chemical Works, Beijing, China). The upper phase was removed to a second tube, dried under $\mathrm{N}_{2}$ and dissolved in acetic ether. FAMEs were analyzed and identified by the comparison of their peaks with a known internal standard 17:0 FAME (Sigma Aldrich, St. Louis, MO, United States).

\section{Illumina-based RNA-seq analysis \\ Library construction and sequencing}

The transgenic GmDof4 strain Dof4-1 and the CK (pCK transgenic strain) were cultured in liquid antibiotic-free Endo medium at $25^{\circ} \mathrm{C}$ under illumination for 120 hours.
Three physical duplicates were cultured simultaneously. Cells at a concentration of approximately $1 \times 10^{7}$ cells/ $\mathrm{mL}$ were collected for library construction and sequencing. In this step we mixed the three physical duplicates as a hybrid sample for RNA isolation. Poly (A) RNA was isolated from $10 \mu \mathrm{g}$ of total RNA and the purified mRNA was first fragmented into small pieces (100$800 \mathrm{bp}$, main band $300-600 \mathrm{bp}$ ) at $94^{\circ} \mathrm{C}$ for exactly 1.5 minutes. Then, double-stranded cDNA was synthesized, and the synthesized cDNA was subjected to endrepair and phosphorylation. Illumina adapters were ligated to the ends of these 3 '-adenylated cDNA fragments. To select a size range of templates for downstream enrichment, the products of ligation reaction were purified on a $2 \%$ TAE-agarose gel. A range of cDNA fragments (350-450 bp) was excised from the gel. Fifteen rounds of PCR amplification were performed to enrich the purified cDNA template. The cDNA library was sequenced on a SE flow cell using Illumina Genome Analyzer IIx (Illumina, San Diego, California, United States). Finally, a total of 70,763,828 raw reads with a length of $80 \mathrm{bp}$ were generated from two GA IIx single-end lanes.

\section{Assembly}

We merged all the sequences from three libraries (another transgenic library was added for assembly) to use as the input data for assembly to obtain a better assembly result. Using SOAPdenovo [50] with the parameters “-K31-d3-R", 56,169 contigs with an N50 contig size of 1,029 bp were obtained.

\section{Detection of differentially expressed gene}

Contigs with a length of at least 300 bp were used as reference sequences. To detect the differentially expressed genes, we first mapped the short reads to the reference genes using the Burrows-Wheeler alignment tool (BWA) program [51] with default parameters. The number of reads mapped to each reference gene was counted as the expression level and the fold-change was calculated after normalization of the total reads for the two libraries. DEGseq detected 1,076 differentially expressed genes with a fold-change higher than two and a false discovery rate less than 0.001 .

\section{Annotation}

For validation and annotation of the assembled contigs, a sequence similarity search was conducted against a non-redundant protein database using the BLASTx algorithm with an $E$ value threshold of $10^{-3}$. The results revealed that out of 13,566 contigs, 7,559 (55.72\%) showed significant similarity to known proteins in the nonredundant $(\mathrm{Nr})$ database. Contigs with a similarity greater than the threshold were annotated using GO 
according to the molecular function, biological process, and cellular component ontologies (http:// www.geneontology.org) by the Blast2GO program [52].

\section{Quantitative real-time PCR (qRT-PCR) assay}

The transgenic GmDof4 strains and the CK were cultured in liquid antibiotic-free Endo medium at $25^{\circ} \mathrm{C}$ under illumination for 120 hours. Then, the total RNA was isolated using EASYspin plant RNA isolation kits (Aidlab Biotechnologies Co., Ltd, Beijing, China). qRTPCR was performed on a LightCycler 480 Real-Time PCR System (Roche Applied Science, Mannheim, Germany) using LightCycler ${ }^{\circ} 480$ SYBR Green I Master (Roche Applied Science, Mannheim, Germany) according to the manufacturer's instructions: 1 cycle of $95^{\circ} \mathrm{C}$ for 30 seconds and then 40 cycles of $95^{\circ} \mathrm{C}$ for $10 \mathrm{sec}-$ onds, followed by $55^{\circ} \mathrm{C}$ for 10 seconds, and $72^{\circ} \mathrm{C}$ for 20 seconds. The primers used for qRT-PCR are shown in Additional file 6: Table S3. Furthermore, the $20 \mu \mathrm{L}$ reaction solution for real-time PCR was composed of $5 \mu \mathrm{L}$ of cDNA, a $0.5 \mu \mathrm{M}$ final concentration of each primer, and $10 \mu \mathrm{L}$ of $2 \times$ real-time PCR Master Mix (Roche Applied Science, Mannheim, Germany). To normalize the amount of transcripts in each sample, the relative abundance of $18 \mathrm{~S}$ rRNA was also determined and was used as the internal standard (forward primer: $5^{\prime}$-CTTGTAAAC CGCGTCGTGATG-3', reverse primer: 5'-GACGTAATC AACGCGAGCTGAT-3'). The gene expression data was analyzed using the $2^{-\Delta \Delta \mathrm{Ct}}$ method [53].

\section{ACCase activity assay}

The ACCase assay of transgenic GmDoft cells and CK was determined according to a previously published method [54]. The transgenic GmDof4 strains and CK were cultured in liquid antibiotic-free Endo medium at $25^{\circ} \mathrm{C}$ under illumination for 120 hours. Then, crude cell extracts were prepared by grinding fresh cells on ice in 2 volumes (w/v) of $50 \mathrm{mM}$ Tris-Cl, $\mathrm{pH} 7.5,100 \mathrm{mM}$ potassium chloride, $5 \mathrm{mM}$ magnesium chloride, $1 \mathrm{mM}$ dithiothreitol, $0.1 \%$ TritonX-100, 10\% (v/v) glycerol, and $0.2 \mathrm{mM}$ Phenylmethanesulfonyl fluoride (Sigma Aldrich, St. Louis, MO, United States). The homogenates were centrifuged for 5 minutes at 3,000 $\times \mathrm{g}$ and were desalted using PD-10 columns. The protein content was determined by the Bradford assay using bovine serum albumin (Sigma Aldrich, St. Louis, MO, United States) as a standard. Reactions $(50 \mu \mathrm{L})$ were initiated by adding $5 \mu \mathrm{L}$ of extract and were stopped with $15 \mu \mathrm{L}$ of $12 \mathrm{~N}$ hydrochloric acid. The reaction mixtures were dried at $55^{\circ} \mathrm{C}$, and the solids were suspended in $30 \mu \mathrm{L}$ of water and were counted in a 1450 liquid scintillation counter (PerkinElmer, Massachusetts, United States). Minus acetyl-CoA controls were included.

\section{Quantitative measurement of neutral lipids and confocal image observation}

Neutral lipids were quantitatively measured using the procedure published by Chen et al. [55]. Chlorella cells grown under nutrient-limited condition were diluted to $\mathrm{OD}_{750}=0.06$, and $5 \mu \mathrm{L}$ samples were introduced into the individual wells of a 96-microplate containing $3 \mu \mathrm{L}$ of a $50 \mu \mathrm{g} / \mathrm{mL}$ Nile red solution (Sigma Aldrich, St. Louis, MO, United States). Then, $292 \mu \mathrm{L}$ of an aqueous solution containing $25 \%$ dimethyl sulfoxide (Sigma Aldrich, St. Louis, MO, United States) was added. The 96-well plate was vortexed $(120 \mathrm{rpm})$ and incubated at $40^{\circ} \mathrm{C}$ for 10 minutes. After the algal cells were stained, the fluorescence emission was recorded using a Varian spectrophotometer (Thermo Fisher Scientific, Rockford, IL, USA) equipped with a 96-well plate reader. Excitation and emission wavelengths of $530 \mathrm{~nm}$ and $575 \mathrm{~nm}$, respectively, were selected. Eight replicates of each treatment were analyzed. Images were acquired using a Zeiss Cell Observer SD (Carl Zeiss Microscopy GmbH, Jena, Germany).

\section{Statistical analysis}

All the experimental data were compared statistically through one-way analysis of variance (ANOVA) using the software Statistical Product and Service Solutions (SPSS) v17.0 followed by Student's t-test to determine the significant difference among the treatment means.

\section{Accession number}

The RNA-Seq data can be found in the GEO library under the accession number [GSE:37473].

\section{Additional files}

Additional file 1: Figure S1. Size distribution of the contigs by RNA-seq. Additional file 2: Figure S2. Cumulative distribution of the $\log 2$ fold change in expression for lipid- and fatty acid-associated genes. The $X$-axis shows the value of the $\log 2$ fold change genes. The $Y$-axis shows the percentage of genes with a $\log 2$ fold change value greater than the corresponding value of the $\mathrm{x}$-axis. There are more upregulated genes than downregulated genes associated with lipid and fatty acid metabolism

Additional file 3: Figure S3. Characterization of transgenic $C$. ellipsoidea expressing GmDof4 under autotrophic culture conditions. (A) Growth curves of transgenic C. ellipsoidea expressing GmDof4 under autotrophic culture conditions for 16 days. (B) Growth rate of transgenic GmDof4 strains compared with the control under autotrophic culture conditions.

Additional file 4: Figure S4. Determination of the GmDof4 gene expression in different transgenic lines by quantitative RT-PCR.

Additional file 5: Table S1. Lipid productivity of C. ellipsoidea under autotrophic culture conditions.

Additional file 6: Table S2. Primers used in vector construction and transformant confirmation. Table S3. Primers used in the quantitative real-time PCR confirmation of differential gene expression. 


\section{Abbreviations}

ACCase: Acetyl-coenzyme A carboxylase; BWA: Burrows-Wheeler alignment tool; dCTP: Deoxycytidine 5'-triphosphate; Dof: DNA binding with one finger; FAS: Fatty acid synthase; GO: Gene ontology; GEO: Gene Expression Omnibus; Nr: Non-redundant; qRT-PCR: Quantitative real-time polymerase chain reaction; RT-PCR: Reverse transcription polymerase chain reaction; SE: Selenite Enrichment; TFs: Transcription factors.

\section{Competing interests}

The authors declare that they have no competing interests.

\section{Authors' contributions}

$J Z, Q H, Y L, R W$ and $Z H$ conceived and designed the study. JZ, QH, WY, LB, LX and CF, and XG performed the experiments. JX, JR and LS assisted in the RNA-seq data analysis. SH and YC assisted in the GC-MS analysis. JZ, QH and ZH analyzed all data and wrote the paper. All authors read and approved the final manuscript.

\section{Acknowledgements}

This research was supported by a project (grant number: 2011CB200902) from the Ministry of Science and Technology of China, a project (grant number: 2011ZX08009-003-004) from the Ministry of Agriculture of China for transgenic research and projects (grant numbers: 21306222 and 21076080 ) from the National Natural Science Foundation of China.

\section{Author details}

${ }^{1}$ Institute of Genetics and Developmental Biology, Chinese Academy of Sciences, Datun Road, Chaoyang District, Beijing 100101, China. ${ }^{2}$ College of Life Sciences, University of Chinese Academy of Sciences, No.19A Yuquan Road, Beijing 100049, China. ${ }^{3}$ Beijing Institute of Genomics, Chinese Academy of Sciences, Beichen West Road \#1, Beijing 100029, China. ${ }^{4}$ State Key Laboratory of Bioreactor Engineering, East China University of Science and Technology, Meilong Road \#130, Shanghai 200237, China. ${ }^{5}$ USDA-ARS, FRRL, Utah State University, 695 N. 1100 E., Logan, UT 84322-6300, USA.

\section{Received: 8 October 2013 Accepted: 20 August 2014}

Published: 4 September 2014

\section{References}

1. Chisti Y: Biodiesel from microalgae. Biotechnol Adv 2007, 25:294-306.

2. Posten C, Schaub G: Microalgae and terrestrial biomass as source for fuels-a process view. J Biotechnol 2009, 142:64-69.

3. Schuhmann H, Lim DK, Schenk PM: Perspectives on metabolic engineering for increased lipid contents in microalgae. Biogeosciences 2012, 3:71-86.

4. Dismukes GC, Carrieri D, Bennette N, Ananyev GM, Posewitz MC: Aquatic phototrophs: efficient alternatives to land-based crops for biofuels. Curr Opin Biotechnol 2008, 19:235-240.

5. Dayananda C, Sarada R, Usha Rani M, Shamala T, Ravishankar G: Autotrophic cultivation of Botryococcus braunii for the production of hydrocarbons and exopolysaccharides in various media. Biomass Bioenerg 2007, 31:87-93.

6. Hu Q, Sommerfeld M, Jarvis E, Ghirardi M, Posewitz M, Seibert M, Darzins A: Microalgal triacylglycerols as feedstocks for biofuel production: perspectives and advances. Plant J 2008, 54:621-639.

7. Rodolfi L, Chini Zittelli G, Bassi N, Padovani G, Biondi N, Bonini G, Tredici MR: Microalgae for oil: Strain selection, induction of lipid synthesis and outdoor mass cultivation in a low-cost photobioreactor. Biotechnol Bioeng 2009, 102:100-112.

8. Soeder CJ: Massive cultivation of microalgae: results and prospects. Hydrobiologia 1980, 72:197-209.

9. Anaga A, Abu GO: A laboratory-scale cultivation of Chlorella and Spirulina using waste effluent from a fertilizer company in Nigeria. Bioresour Technol 1996, 58:93-95.

10. Hatano S, Kabata K, Sadakane H: Transition of lipid synthesis from chloroplasts to a cytoplasmic system during hardening in Chlorella ellipsoidea. Plant Physiol 1981, 67:216-220.

11. Hatano S, Kabata K, Yoshimoto M, Sadakane H: Accumulation of free fatty acids during hardening of Chlorella ellipsoidea. Plant Physiol 1982 70:1173-1177

12. Otsuka H, Morimura Y: Change of fatty acid composition of Chlorella ellipsoidea during its cell cycle. Plant Cell Physiol 1966, 7:663-670.
13. Hatano S, Sadakane H, Tutumi M, Watanabe T: Studies on frost hardiness in Chlorella ellipsoidea I. Development of frost hardiness of Chlorella ellipsoidea in synchronous culture. Plant Cell Physiol 1976, 17:451-458.

14. Li Y, Horsman M, Wang B, Wu N, Lan CQ: Effects of nitrogen sources on cell growth and lipid accumulation of green alga Neochloris oleoabundans. Appl Microbiol Biotechnol 2008, 81:629-636.

15. Schnurr PJ, Espie GS, Allen DG: Algae biofilm growth and the potential to stimulate lipid accumulation through nutrient starvation. Bioresour Technol 2013, 136:337-344.

16. Trentacoste EM, Shrestha RP, Smith SR, Glé C, Hartmann AC, Hildebrand M, Gerwick WH: Metabolic engineering of lipid catabolism increases microalgal lipid accumulation without compromising growth. Proc Natl Acad Sci U S A 2013, 110:19748-19753.

17. Niu Y, Zhang M, Li D, Yang W, Liu J, Bai W, Li H: Improvement of neutral lipid and polyunsaturated fatty acid biosynthesis by overexpressing a type 2 diacylglycerol acyltransferase in marine diatom Phaeodactylum tricornutum. Mar Drugs 2013, 11:4558-4569.

18. Courchesne NMD, Parisien A, Wang B, Lan CQ: Enhancement of lipid production using biochemical, genetic and transcription factor engineering approaches. J Biotechnol 2009, 141:31-41.

19. Yanagisawa S, Schmidt RJ: Diversity and similarity among recognition sequences of Dof transcription factors. Plant J 1999, 17:209-214.

20. Papi M, Sabatini S, Altamura MM, Hennig L, Schäfer E, Costantino $P$, Vittorioso P: Inactivation of the phloem-specific Dof zinc finger gene DAG1 affects response to light and integrity of the testa of Arabidopsis seeds. Plant Physiol 2002, 128:411-417.

21. Mena M, Vicente-Carbajosa J, Schmidt RJ, Carbonero P: An endosperm-specific DOF protein from barley, highly conserved in wheat, binds to and activates transcription from the prolamin-box of a native B-hordein promoter in barley endosperm. Plant J 1998, 16:53-62.

22. Shaw LM, McIntyre CL, Gresshoff PM, Xue G-P: Members of the Dof transcription factor family in Triticum aestivum are associated with light-mediated gene regulation. Funct Integr Genomics 2009, 9:485-498.

23. Wang H, Zhang B, Hao Y, Huang J, Tian A, Liao Y, Zhang J, Chen S: The soybean Dof-type transcription factor genes, GmDof4 and GmDof11, enhance lipid content in the seeds of transgenic Arabidopsis plants. Plant J 2007, 52:716-729.

24. Ashburner M, Ball CA, Blake JA, Botstein D, Butler H, Cherry JM, Davis AP, Dolinski K, Dwight SS, Eppig JT: Gene Ontology: tool for the unification of biology. Nat Genet 2000, 25:25-29.

25. Singh J, Gu S: Commercialization potential of microalgae for biofuels production. Renew Sust Energ Rev 2010, 14:2596-2610.

26. Xiong W, Gao C, Yan D, Wu C, Wu Q: Double $\mathrm{CO}_{2}$ fixation in photosynthesis-fermentation model enhances algal lipid synthesis for biodiesel production. Bioresour Technol 2010, 101:2287-2293.

27. Greenwell $H$, Laurens L, Shields R, Lovitt R, Flynn K: Placing microalgae on the biofuels priority list: a review of the technological challenges. $J R$ Soc Interface 2010, 7:703-726

28. Chen $H$, Wang F, Dong $Y$, Wang $N$, Sun $Y$, Li X, Liu L, Fan X, Yin H, Jing $Y$ Sequence mining and transcript profiling to explore differentially expressed genes associated with lipid biosynthesis during soybean seed development. BMC Plant Biol 2012, 12:122.

29. Rismani-Yazdi H, Haznedaroglu BZ, Hsin C, Peccia J: Transcriptomic analysis of the oleaginous microalga Neochloris oleoabundans reveals metabolic insights into triacylglyceride accumulation. Biotechnol Biofuels 2012, 5:74.

30. Guarnieri MT, Nag A, Smolinski SL, Darzins A, Seibert M, Pienkos PT: Examination of triacylglycerol biosynthetic pathways via de novo transcriptomic and proteomic analyses in an unsequenced microalga. PLoS One 2011, 6:e25851.

31. Huerlimann R, Heimann K: Comprehensive guide to acetyl-carboxylases in algae. Crit Rev Biotechnol 2013, 33:49-65.

32. Ryu SB, Karlsson BH, Özgen M, Palta JP: Inhibition of phospholipase D by lysophosphatidylethanolamine, a lipid-derived senescence retardant. Proc Natl Acad Sci U S A 1997, 94:12717-12721.

33. Blanc G, Duncan G, Agarkova I, Borodovsky M, Gurnon J, Kuo A, Lindquist E, Lucas S, Pangilinan J, Polle J: The Chlorella variabilis NC64A genome reveals adaptation to photosymbiosis, coevolution with viruses, and cryptic sex. Plant Cell 2010, 22:2943-2955.

34. Yu W, Ansari W, Schoepp NG, Hannon MJ, Mayfield SP, Burkart MD: Modifications of the metabolic pathways of lipid and triacylglycerol production in microalgae. Microb Cell Fact 2011, 10:91. 
35. Hockin NL, Mock T, Mulholland F, Kopriva S, Malin G: The response of diatom central carbon metabolism to nitrogen starvation is different from that of green algae and higher plants. Plant Physiol 2012, 158:299-312.

36. Appleyard RK: Segregation of new lysogenic types during growth of a doubly lysogenic strain derived from Escherichia coli K12. Genetics 1954, 39:440-452.

37. McLeod G: Delayed light action spectra of several algae in visible and ultraviolet light. J Gen Physiol 1958, 42:243-250.

38. Taylor M, Vasil V, Vasil I: Enhanced GUS gene expression in cereal/grass cell suspensions and immature embryos using the maize uhiquitin-based plasmid pAHC25. Plant Cell Rep 1993, 12:491-495.

39. Bai L, Yin W, Chen Y, Niu L, Sun Y, Zhao S, Yang F, Wang RRC, Wu Q, Zhang $X$ Hu Z: A new strategy to produce a defensin: stable production of mutated NP-1 in nitrate reductase-deficient Chlorella ellipsoidea. PLoS One 2013, 8:e54966.

40. Nichols HW: Growth media-freshwater. In Handbook of Phycological Methods: Culture Methods and Growth Measurements. Edited by Stein JR. Cambridge: Cambridge University Press; 1973:7-24.

41. Chomczynski P, Sacchi N: Single-step method of RNA isolation by acid guanidinium thiocyanate-phenol-chloroform extraction. Anal Biochem 1987, 162:156-159.

42. Sambrook J, Russell DW: Molecular Cloning: a Laboratory Manual (3-volume set). New York: Cold Spring Harbor Laboratory Press; 2001

43. White PA, Kalff J, Rasmussen JB, Gasol JM: The effect of temperature and algal biomass on bacterial production and specific growth rate in freshwater and marine habitats. Microb Ecol 1991, 21:99-118.

44. Miao X, Wu Q: High yield bio-oil production from fast pyrolysis by metabolic controlling of Chlorella protothecoides. J Biotechnol 2004, 110:85-93.

45. Rausch $\mathrm{T}$ : The estimation of micro-algal protein content and its meaning to the evaluation of algal biomass I. Comparison of methods for extracting protein. Hydrobiologia 1981, 78:237-251.

46. Bradford MM: A rapid and sensitive method for the quantitation of microgram quantities of protein utilizing the principle of protein-dye binding. Anal Biochem 1976, 72:248-254.

47. Folch J, Lees M, Sloane-Stanley G: A simple method for the isolation and purification of total lipids from animal tissues. J Biol Chem 1957, 226:497-509.

48. Kattner G, Fricke HS: Simple gas-liquid chromatographic method for the simultaneous determination of fatty acids and alcohols in wax esters of marine organisms. J Chromatogr A 1986, 361:263-268.

49. Song L, Lu W, Hu J, Zhang Y, Yin W, Chen Y, Hao S, Wang B, Wang RR, Hu Z: Identification and functional analysis of the genes encoding $\Delta 6$-desaturase from Ribes nigrum. J Exp Bot 2010, 61:1827-1838.

50. Li R, Yu C, Li Y, Lam T, Yiu S, Kristiansen K, Wang J: SOAP2: an improved ultrafast tool for short read alignment. Bioinformatics 2009, 25:1966-1967.

51. Li H, Durbin R: Fast and accurate short read alignment with Burrows-Wheeler transform. Bioinformatics 2009, 25:1754-1760.

52. Conesa A, Götz S, García-Gómez JM, Terol J, Talón M, Robles M: Blast2GO: a universal tool for annotation, visualization and analysis in functional genomics research. Bioinformatics 2005, 21:3674-3676.

53. Livak KJ, Schmittgen TD: Analysis of relative gene expression data using real-time quantitative PCR and the $2^{-\Delta \Delta \mathrm{Ct}}$ method. Methods 2001, 25:402-408

54. Andre C, Haslam RP, Shanklin J: Feedback regulation of plastidic acetyl-CoA carboxylase by 18: 1-acyl carrier protein in Brassica napus. Proc Natl Acad Sci U S A 2012, 109:10107-10112.

55. Chen W, Zhang C, Song L, Sommerfeld M, Hu Q: A high throughput Nile red method for quantitative measurement of neutral lipids in microalgae. J Microbiol Methods 2009, 77:41-47.

doi:10.1186/s13068-014-0128-4

Cite this article as: Zhang et al:: Overexpression of the soybean transcription factor GmDof4 significantly enhances the lipid content of Chlorella ellipsoidea. Biotechnology for Biofuels 2014 7:128.

\section{Submit your next manuscript to BioMed Central and take full advantage of:}

- Convenient online submission

- Thorough peer review

- No space constraints or color figure charges

- Immediate publication on acceptance

- Inclusion in PubMed, CAS, Scopus and Google Scholar

- Research which is freely available for redistribution

Submit your manuscript at www.biomedcentral.com/submit 